УДК 622.311

\title{
ВЛИЯНИЕ ТЕРМООБРАБОТКИ НА СОСТАВ И СВОЙСТВА РАЗНОТИПНЫХ ТОРФОВ ТОМСКОЙ ОБЛАСТИ
}

\author{
(C) Н.В. Чухарева
}

\author{
Национальный исследовательский Томский политехнический университет, \\ пр. Ленина, 30, Томск, 634034 (Россия)
}

Дана оценка влияния термообработки на изменение группового и элементного состава разнотипного торфа, его химической структуры по ИК-спектрам и его парамагнитных свойств. Показано, что после термообработки сохраняется влияние особенностей, обусловленных торфообразовательными процессами, но глубина преобразований исходного вещества в результате предварительного нагрева определяется типом торфа.

Ключевые слова: торф, термообработка, элементный состав, ИК-спектроскопия.

\section{Введение}

Известно, что торф является органическим сырьем для получения ценных компонентов для сельскохозяйственного и промышленного назначения. Весь комплекс полезных свойств зависит от его состава и структуры, определяется условиями образования.

В настоящее время для получения торфа с заданными свойствами применяют различные способы воздействия на исходное вещество. Одним из таких способов является способ термического воздействия при температуре $250^{\circ} \mathrm{C}$ в среде газов разложения [1,2]. Как было показано в исследованиях [1-3], он позволяет увеличивать выход ценных компонентов: битумов и гуминовых кислот. При этом его характеристики изменяются в разной степени, в разной степени происходит преобразование органической и неорганической составляющей торфяной матрицы. Поэтому возникает достаточно сложный вопрос: от чего зависит глубина преобразований торфа под влиянием термического воздействия? Чтобы попытаться ответить на него, требуются данные о разнотипных объектах.

Целью представленной работы является исследование глубины влияния термообработки на состав и свойства разнотипных торфов месторождений Томской области.

\section{Экспериментальная часть}

В представленной работе для исследования выбран торф верхового и низинного типа месторождений Томской области средней степени разложения $(\mathrm{R}=25-45 \%)$ травяно-моховой и травяной групп. Был изучен ботанический состав и проведен технический анализ по методикам [4-7]. Характеристики объектов приведены в таблице 1.

Термическую обработку измельченного до 0,25 мм торфа проводили на лабораторной установке со скоростью нагрева 5 град/мин по методике [1-2]. Что бы оценить влияние нагрева на изменение группового состава, было проведено извлечение составляющих (ГС) из исходных и модифицированных торфов по методике [8]. Далее был проведен анализ образцов на содержание C, H, N, O+S элементов по методике [9].

Оптические свойства торфа были исследованы методом ИК-спектроскопии. Спектры ИК были получены в Национальном исследовательском Томском политехническом университете на спектрометре ИК-Фурье, Nicolet iS10 корпорации Termo Fisher Scientific (США), оснащенном приставкой нарушенного полного внутреннего отражения (HПВО) с кристаллом из ZnSe. Параметры эксперимента: разрешение $-4 \mathrm{~cm}^{-1}$, число сканов пробы и спектра сравнения - 128, диапазон сканирования от 4000 до $650 \mathrm{~cm}^{-1}$. Регистрацию и обработку спектров проводили в программе Omnic 8.3. Для устранения наклона базовой линии, возникающего при использовании метода НПВО, проводили ее автоматическую коррекцию. Для учета эффектов сдвига полос поглощения и

Чухарева Наталья Вячеславовна - кандидат химических наук, доцент, e-mail: Natasha@tpu.ru влияния длины волны на глубину проникновения в образец проводили НПВО коррекцию спектров. 
Таблица 1. Характеристика объектов исследования

\begin{tabular}{|c|c|c|c|c|c|c|}
\hline \multirow{2}{*}{ Вид торфа, шифр } & \multirow{2}{*}{ Группа } & \multirow{2}{*}{$\mathrm{R}, \%$} & \multirow{2}{*}{$\begin{array}{c}\text { Растения-торфообразователи, } \\
\text { (содержание, \%) }\end{array}$} & \multicolumn{3}{|c|}{ Технический анализ *, \% } \\
\hline & & & & $W^{a}$ & $A^{d}$ & $V^{\text {daf }}$ \\
\hline \multicolumn{7}{|c|}{ верховой торф } \\
\hline $\begin{array}{l}\text { Пушицево- } \\
\text { сфагновый } \\
\text { (B1, В2) }\end{array}$ & $\begin{array}{l}\text { травяно- } \\
\text { моховая }\end{array}$ & 25 & $\begin{array}{l}\text { пушица (50), сфагнум ангустифолиум } \\
\text { (30), сфагнум магелланикум (10), сфаг- } \\
\text { нум-фускум (5), кустарнички, сосна (5) } \\
\text { пушица (80), сфагнум фускум (5), сфаг- } \\
\text { нум магелланикум (5), сфагнум ангу- } \\
\text { стифолиум (5), кустарнички, сосна (5) }\end{array}$ & 8,2 & 1,9 & 73,5 \\
\hline $\begin{array}{c}\text { Шейхцериевый } \\
\text { (B3) }\end{array}$ & травяная & 40 & $\begin{array}{c}\text { шейхцерия (60), сфагнум магелланикум } \\
\text { (10), сфагнум ангустифолиум (10) сфаг- } \\
\text { нум фускум (5), пушица (5), осока топя- } \\
\text { ная (5), сосна (5) }\end{array}$ & 40 & 11,1 & 7,8 \\
\hline \multicolumn{7}{|c|}{ низинный торф } \\
\hline \multirow{2}{*}{$\begin{array}{c}\text { Осоково-гипновый } \\
(\mathrm{H} 1, \mathrm{H} 2)\end{array}$} & $\begin{array}{l}\text { травяно- } \\
\text { моховая }\end{array}$ & 25 & $\begin{array}{c}\text { гипновые мхи (50), осока топяная (25), } \\
\text { осока вздутая (15), вахта (5), древесные } \\
\text { остатки (5) }\end{array}$ & 8,2 & 8,9 & 70,7 \\
\hline & $\begin{array}{l}\text { травяно- } \\
\text { моховая }\end{array}$ & 45 & $\begin{array}{c}\text { гипновые мхи (65), вахта (10), осока } \\
\text { вздутая (10), осока топяная (5), сфагнум } \\
\text { магелланикум (5), кустарник березы (5) }\end{array}$ & 8,1 & 6,4 & 70,4 \\
\hline Осоковый (Н3) & травяная & 35 & $\begin{array}{c}\text { осока вздутая (65), осока топяная (5), } \\
\text { хвощ (5), Вахта (10), травяные остатки } \\
(15)\end{array}$ & 10,2 & 9,9 & 68,4 \\
\hline
\end{tabular}

* $\mathbf{W}^{\mathbf{a}}-$ влажность аналитической пробы, $\mathbf{A}^{\mathbf{d}}-$ зольность на сухое вещество, $\mathbf{V}^{\text {daf }}-$ выход летучих веществ на горючую мaccy

Проведены исследования парамагнитных свойств торфа в Новосибирском институте органической химии СО РАН на ЭПР-радиоспектрометре Bruker ELEXSYS E-540: Х-диапазон при частоте СВЧизлучения 10 ГГц в высокодобротном цилиндрическом резонаторе, $g$-фактор был определен по спектрам с использованием внутреннего частотометра прибора с калибровочной поправкой относительно $g$-фактора DPPH. Измерения проводили на мощности $10 \mathrm{~dB}$ в ампулах для ЭПР, внутренним диаметром 5 мм.

Определение содержания спинов осуществлялось по методике, разработанной фирмой «Bruker»Absolute spins, исходя из измерения добротности резонатора при мощности СВЧ-поля $33 \mathrm{~dB}$ без применения внешнего эталона. Расчет осуществлялся в предположении дублетного состояния электронной оболочки $(\mathrm{S}=1 / 2)$. Точности определения содержания спинов: $\pm 15 \%$.

\section{Результаты и обсуждение}

Полученные данные по исследованию групповых компонентов, содержащихся в торфе (табл. 2), свидетельствуют о наибольшем выходе битумов (Б), фульвокислот (ФК), целлюлозы (Ц), и незначительно для суммы водорастворимых и легкогидролизуемых веществ (ЛГВ+ВРВ) для образцов верхового торфа по сравнению с образцами Н1/H2/H3. Выход гуминовых кислот (ГК) и негидролизуемого остатка (НГО) лежит в более низких областях. После термообработки данная закономерность сохранилась, что указывает на сохранение особенностей, обусловленных влиянием торфообразовательных процессов на исходное вещество. Но глубина преобразования, выраженная через относительное изменение выходов отдельных групповых составляющих $(\Delta \Gamma \mathrm{C})$, для верховых и низинных торфов получена разная. Показано, что для Н1/H2/H3, в сравнении с В1/B2/B3: в набольшей степени изменилось содержание битумов $(\Delta \mathrm{Б}=+23,3 \ldots+67,5 \%$ отн. $)$ и фульвокислот ( $\Delta \Phi К=-21,3 \ldots-23,1 \%$ отн.); остальные значения $\Delta \Gamma \mathrm{C}$ для торфа низинного типа имеют пониженные значения.

Результаты проведенного элементного анализа торфа также позволили выделить особенности, обусловленные влиянием предварительной термообработки. Так, после нагрева торфа возрастает содержание углерода и азота, содержание водорода и $(\mathrm{O}+\mathrm{S})$ - снижается (табл. 3). Полученное отражает характер изменений органического вещества торфа при термообработке до $250^{\circ} \mathrm{C}$ в среде собственных газов деструкции, который, согласно исследованиям $[3,10,11]$, сопровождается его разложением с образованием оксида и диоксида углерода (реакции декарбоксилирования) и пирогенетической воды (реакции дегидратации) наряду с одновременным протеканием реакций конденсации ароматических фрагментов структуры. 
Таблица 2. Групповой состав торфа

\begin{tabular}{|c|c|c|c|c|c|c|c|}
\hline \multirow{2}{*}{ Торф } & \multirow{2}{*}{$\mathrm{T},{ }^{\circ} \mathrm{C}$} & \multicolumn{6}{|c|}{ Групповой состав, \% на daf } \\
\hline & & Б & ВРВ +ЛГВ & $\Phi К$ & ГК & Ц & НГО \\
\hline \multicolumn{8}{|c|}{ верховой торф } \\
\hline \multirow{2}{*}{$\mathrm{B} 1 / \mathrm{B} 2 / \mathrm{B} 3$} & - & \multirow{2}{*}{$\begin{array}{l}6,3 / 8,2 / 8,0 \\
6,8 / 9,0 / 8,6 \\
\end{array}$} & \multirow{2}{*}{$\begin{array}{l}32,6 / 31,3 / 30,3 \\
27,2 / 25,1 / 26,9 \\
\end{array}$} & \multirow{2}{*}{$\begin{array}{l}18,3 / 18,6 / 19,7 \\
15,1 / 14,9 / 16,2 \\
\end{array}$} & \multirow{2}{*}{$\begin{array}{l}25,0 / 28,0 / 28,9 \\
31,0 / 35,0 / 34,0 \\
\end{array}$} & $5,4 / 5,7 / 2,8$ & $12,4 / 8,2 / 10,3$ \\
\hline & 250 & & & & & $4,8 / 5,1 / 2,6$ & $15,1 / 10,9 / 12,0$ \\
\hline \multicolumn{8}{|c|}{ изменение содержания ГС для верхового торфа в результате термообработки, \% отн. } \\
\hline$\Delta \mathrm{Б}$ & \multicolumn{2}{|c|}{$\triangle \mathrm{BPB}+Л Г \mathrm{~B}$} & $\Delta \Phi K$ & $\Delta \Gamma K$ & $\Delta Ц$ & $\Delta \mathrm{HГО}$ & $\Delta \mathrm{Б}$ \\
\hline$+7,5 \ldots+9,6$ & \multicolumn{2}{|c|}{$-11,2 \ldots-19,8$} & $-17,5 \ldots-19,9$ & $+17,6 \ldots+25,0$ & $-7,1 \ldots-11,1$ & $+16,5 \ldots+32,9$ & $+7,5 \ldots+9,6$ \\
\hline \multicolumn{8}{|c|}{ низинный торф } \\
\hline \multirow{2}{*}{$\mathrm{H} 1 / \mathrm{H} 2 / \mathrm{H} 3$} & \multirow{2}{*}{$\begin{array}{c}- \\
250\end{array}$} & \multirow{2}{*}{$\begin{array}{l}3,0 / 3,1 / 2,9 \\
3,7 / 3,3 / 3,4 \\
\end{array}$} & $33,5 / 28,3 / 26,2$ & \multirow{2}{*}{$\begin{array}{l}13,0 / 13,0 / 12,7 \\
10,2 / 10,0 / 10,0 \\
\end{array}$} & \multirow{2}{*}{\begin{tabular}{|l|}
$30,0 / 38,0 / 40,0$ \\
$36,0 / 42,0 / 44,0$
\end{tabular}} & $2,3 / 1,7 / 1,9$ & $18,2 / 15,9 / 16,5$ \\
\hline & & & $27,6 / 25,0 / 22,8$ & & & $2,2 / 1,6 / 1,8$ & $20,3 / 18,1 / 18,0$ \\
\hline \multicolumn{8}{|c|}{ изменение содержания ГС для низинного торфа в результате термообработки, \% отн. } \\
\hline \multicolumn{2}{|l|}{$\Delta \mathrm{Б}$} & $\triangle \mathrm{BPB}+Л Г \mathrm{~B}$ & $\Delta \Phi \mathrm{K}$ & \multirow{2}{*}{$\begin{array}{r}\frac{\Delta \Gamma \mathrm{K}}{+10,0 \ldots} \\
+0\end{array}$} & \multirow{2}{*}{\multicolumn{2}{|c|}{$\frac{\Delta Ц}{-4,3 \ldots-5,9}$}} & $\Delta \mathrm{HГO}$ \\
\hline$+23,3 \ldots+6$ & & $-11,7 \ldots-17,6$ & $-21,3 \ldots-2$ & & & & $+7,5 \ldots+11,5$ \\
\hline
\end{tabular}

Таблица 3. Элементный состав торфа

\begin{tabular}{|c|c|c|c|c|c|}
\hline \multirow{2}{*}{ Торф } & \multirow{2}{*}{$\mathrm{T},{ }^{\circ} \mathrm{C}$} & \multicolumn{4}{|c|}{ Элементный состав, \% на daf } \\
\hline & & $\mathrm{C}$ & $\mathrm{H}$ & $\mathrm{N}$ & $\mathrm{O}+\mathrm{S}^{*}$ \\
\hline \multicolumn{6}{|c|}{ верховой торф } \\
\hline \multirow{2}{*}{$\mathrm{B} 1 / \mathrm{B} 2 / \mathrm{B} 3$} & - & $55,8 / 57,1 / 57,9$ & $6,0 / 6,0 / 5,9$ & $1,5 / 1,3 / 2,5$ & $36,7 / 35,6 / 33,7$ \\
\hline & 250 & $58,7 / 62,2 / 59,8$ & $5,8 / 6,0 / 5,7$ & $2,3 / 1,9 / 3,1$ & $33,2 / 29,9 / 31,4$ \\
\hline \multicolumn{6}{|c|}{ изменение содержания элементов верхового торфа в результате термообработки, \% отн. } \\
\hline \multicolumn{2}{|c|}{$\Delta \mathrm{C}$} & $\Delta \mathrm{H}$ & \multicolumn{2}{|c|}{$\Delta \mathrm{N}$} & $\Delta \mathrm{O}+\mathrm{S}$ \\
\hline \multicolumn{2}{|c|}{$+3,4 \ldots+8,8$} & \multirow[t]{2}{*}{$-2,0 \ldots-3,4$} & \multicolumn{2}{|c|}{$+27,1 \ldots+51,9$} & $-6,8 \ldots 16,0$ \\
\hline \multicolumn{5}{|c|}{ низинный торф } & \\
\hline \multirow{2}{*}{$\mathrm{H} 1 / \mathrm{H} 2 / \mathrm{H} 3$} & - & $43,4 / 53,7 / 52,8$ & $5,6 / 6,1 / 6,3$ & $5,9 / 2,9 / 4,5$ & $45,1 / 37,3 / 36,4$ \\
\hline & 250 & $54,6 / 59,6 / 58,1$ & $5,3 / 5,7 / 5,8$ & $6,3 / 3,5 / 4,6$ & $33,8 / 31,2 / 31,5$ \\
\hline \multicolumn{6}{|c|}{ изменение содержания элементов низинного торфа в результате термообработки, \% отн. } \\
\hline \multicolumn{2}{|c|}{$\Delta \mathrm{C}$} & $\Delta \mathrm{H}$ & \multicolumn{2}{|c|}{$\Delta \mathrm{N}$} & $\Delta \mathrm{O}+\mathrm{S}$ \\
\hline \multicolumn{2}{|c|}{$+9,9 \ldots+25,9$} & $-4,7 \ldots-8,0$ & \multicolumn{2}{|c|}{$+4,3 \ldots+19,2$} & $-7,1 \ldots-15,3$ \\
\hline
\end{tabular}

После термообработки сохраняются закономерности по содержанию элементов, аналогично исходным образцам: большее содержание углерода и водорода в термообработанном торфе верхового типа; большее содержание азота и $\mathrm{O}+\mathrm{S}$ - в термообработанном торфе низинного типа.

Степень изменения элементного состава различна: в верховом торфе наибольшие изменения характерны по содержанию азота ( $\Delta \mathrm{N}$ от $+27,1$ до $+51,9 \%$ отн. $)$, а для низинного - изменения по содержанию углерода $\Delta \mathrm{C}$ и водорода $\Delta \mathrm{H}$.

В ИК-спектрах образцов В1/В2/В3 и Н1/Н2/Н3 наблюдаются типичные для торфов полосы поглощения в области валентных колебаний ОН-групп (3400 см ${ }^{-1}$ ), связанных межмолекулярными водородными связями; полосы поглощения в области валентных колебаний метиленовых $\mathrm{CH}_{2}$-групп и метильных $\mathrm{CH}_{3}$ групп (2920 см ${ }^{-1}$ и $\left.2850 \mathrm{~cm}^{-1}\right)$, в области валентных колебаний карбоксильных C=O-групп $\left(1725-1700 \mathrm{~cm}^{-1}\right)$ и $\mathrm{C}=\mathrm{C}$ полисопряженных ароматических систем и моноароматических структур (1620-1600 см ${ }^{-1}$ и $1520-$ $1500 \mathrm{~cm}^{-1}$ ). Наблюдаются слабовыраженные полосы поглощения в области деформационных колебаний $\mathrm{C}-\mathrm{CH}_{3}$-групп (1390-1370 см ${ }^{-1}$ ) и в области валентных колебаний С-О-групп кислот, фенолов (1250$1200 \mathrm{~cm}^{-1}$ ). Полоса 1100-1000 $\mathrm{cm}^{-1}$, согласно [12], соответствует валентным колебаниям С-О-групп спиртов. В области менее $1000 \mathrm{~cm}^{-1}$ идентификацию полос поглощения не проводили, торф не был обеззолен (здесь оказывают сильное влияние минеральные вещества).

Все образцы проявляют однотипность функционального состава, схожесть которого прослеживается при сравнении ИК-спектров всех исследованных объектов с торфами других регионов [12-13]. Особенности функционального состава, обусловленные типом торфа, сохраняются после его термической обработки в рассматриваемых условиях (рис. 1). 


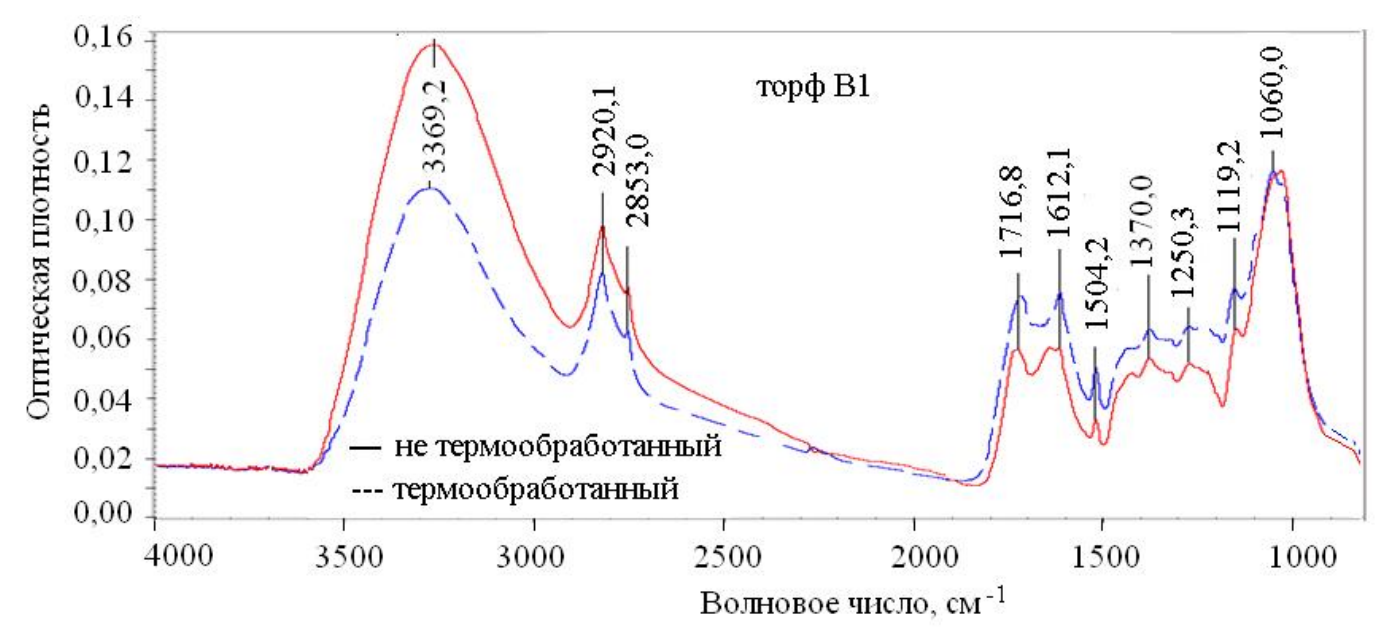

Рис. 1. ИК-спектры пушицево-сфагнового торфа, $\mathrm{R}=25 \%$

В результате термообработки торфа в ИК-спектрах отмечается понижение интенсивности валентных колебаний ОН-групп и С-Н-групп при $3400 \mathrm{~cm}^{-1}$ и $2920 \mathrm{~cm}^{-1}$, что, подтверждает процессы реакций дегидратации при низкотемпературной термической деструкции. Происходит увеличение интенсивности полос поглощения C=O-групп при 1725-1700 см ${ }^{-1}$ и С-О-групп кислот, фенолов при 1250-1200 см ${ }^{-1}$, что указывает на изменение функционального состава вследствие взаимодействия продуктов термического разложения торфа (сложные эфиры, альдегиды, кетоны) с пирогенетической водой с образованием новых карбоксильных групп. Полученное хорошо согласуется с работами [1-3, 14], при этом более сильные изменения характерны для образцов В1/В2/В3.

Полученные данные электронного парамагнитного резонанса свидетельствуют, что термообработка приводит к существенному возрастанию сигнала ЭПР. Происходит увеличение концентрации парамагнитных центров (табл. 4). Причиной таких результатов, согласно [15], может являться повышение степени ароматического полисопряжения исходного вещества торфа, произошедшего вследствие образования дополнительных систем полисопряжения в результате протекания реакций конденсации, и согласование этих данных с повышенным содержанием углерода в элементном составе, с увеличением интенсивности ИКсигналов в области $\mathrm{C}=\mathrm{O}$-групп и повышением содержания в составе модифицированных торфов гуминовых кислот, характеризующихся, как известно, более высоким уровнем парамагнетизма.

Таблица 4. Электронный парамагнитный резонанс торфов

\begin{tabular}{|c|c|c|c|}
\hline Торф & $\mathrm{T},{ }^{\circ} \mathrm{C}$ & Число спинов с s=1/2, I $10^{17}$ спин /г & g-фактор узкого синглета \\
\hline \multicolumn{4}{|c|}{ верховой торф } \\
\hline \multirow{2}{*}{$\mathrm{B} 1 / \mathrm{B} 2 / \mathrm{B} 3$} & - & $0,239 / 0,362 / 0,367$ & $2,0020 / 2,0018 / 2,0019$ \\
\hline & 250 & $2,042 / 2,700 / 3,322$ & $2,0061 / 2,0060 / 2,0061$ \\
\hline \multicolumn{4}{|c|}{ низинный торф } \\
\hline \multirow{2}{*}{$\mathrm{H} 1 / \mathrm{H} 2 / \mathrm{H} 3$} & - & $0,065 / 0,093 / 0,099$ & $2,0018 / 2,0022 / 2,0024$ \\
\hline & 250 & $2,521 / 0,916 / 1,641$ & $2,0064 / 2,0064 / 2,0063$ \\
\hline
\end{tabular}

\section{Выводы}

1. Термообработка разнотипного торфа способствует увеличению битумов, гуминовых кислот и негидролизуемого остатка в их групповом составе, содержание остальных компонентов снижается.

2. Различия, обусловленные влиянием типа торфа на содержание групповых составляющих, сохраняются после его предварительной термообработки в приведенных условиях.

3. Степень влияния термообработки торфа на содержание групповых составляющих определяется его типом: набольшие относительные изменения содержания битумов и фульвокислот характерны для торфа низинного типа, а наибольшие относительные изменения содержания гуминовых кислот, целлюлозы и негидролизуемого остатка - для верхового торфа.

4. Термообработка торфа приводит к увеличению содержания в элементном составе углерода и азота.

5. После термообработки сохраняется влияние типа торфа на элементный состав. 
6. Наибольшие относительные изменения содержания углерода и водорода получены для торфа низинного типа, для верхового торфа в большей степени изменяется содержание азота.

7. В ИК-спектрах термообработанных разнотипных образцов сохраняются типичные для торфов полосы поглощения.

8. В результате термообработки торфа в ИК-спектрах отмечено понижение интенсивности валентных колебаний ОН-групп и С-Н-групп при $3400 \mathrm{~cm}^{-1}$ и $2920 \mathrm{~cm}^{-1}$ и увеличение интенсивности полос поглощения С=О-групп при 1725-1700 см${ }^{-1}$ и С-О-групп кислот, фенолов при 1250-1200 см${ }^{-1}$, что свидетельствует о протекании реакций дегидратации и дальнейшим взаимодействием пирогенетической воды с продуктами термического разложения торфа и образованием новых карбоксильных групп.

9. Термообработка торфа способствует усилению парамагнитных свойств, выраженных через возрастание сигнала ЭПР и концентрацию парамагнитных центров.

\section{Список литературы}

1. Тарновская Л.И., Маслов С.Г., Смольянинов С.И. Химический состав органического вещества твердых остатков термолиза торфа // Химия твердого топлива. 1988. №3. С. 26-29.

2. Чухарева Н. В. Исследование кинетики термически активированных изменений состава и свойств торфяных гуминовых кислот: автореф. дис. ... канд. хим. наук. Томск, 2003. 23 с.

3. Баженов Д.А. Моделирование физико-химических закономерностей низкотемпературного разложения торфа: дис. ... канд. хим. наук. Томск, 2000. 165 с.

4. ГОСТ 28245-89. Торф. Методы определения ботанического состава и степени разложения. М., 2006. 7 с.

5. ГОСТ 11305-83. Торф. Методы определения влаги. М.,1988. 8 с.

6. ГОСТ 11306-83. Торф и продукты его переработки. Методы определения зольности. М., 1995. 8 с.

7. ГОСТ 6382-2001. Топливо твердое минеральное. Методы определения выхода летучих веществ. М., 2002. $20 \mathrm{c}$.

8. Лиштван И.И., Король Н.Т. Основные свойства торфа и методы их определения. Минск, 1975. 320 с.

9. Fadeeva V.P., Tikhova V.D., Nikulicheva O.N. Elemental Analysis of Organic Compounds with the Use of Automated CHNS Analyzers // Journal of analytical chemistry. 2008. Vol. 63, N11. Pp. 1094-1106.

10. Раковский В.Е., Пигулевская Л.В. Химия и генезис торфа. М., 1978. 231 с.

11. Лиштван И.И. Физико-химические свойства торфа, химическая и термическая его переработка // Химия твердого топлива. 1996. №3. С. 3-23.

12. Ларина Г.В., Иванов А.А., Казанцева Н.А. Групповой состав органического вещества торфов Горного Алтая и некоторые структурные характеристики гуминовых кислот // Вестник ТГПУ. 2009. Вып. 3(81). C. $110-115$.

13. Harrison B., Ellis J., Broadhurst D., Reid K., Goodacre R., Priest F.G. Differentiation of Peats Used in the Preparation of Malt for Scotch Whisky Production Using Fourier Transform Infrared Spectroscopy // Journal of the institute of Brewing. 2006. Vol. 112, N4. Pp. 333-339.

14. Тарновская Л.И. Закономерности изменения группового состава торфа в процессе термолиза: дис. ... канд. техн. наук. Томск, 1985. 199 с.

15. Марыганова В.В., Бамбалов Н.Н., Стигуцкий В.П., Пармон С.В. Изменение состава гуминовых веществ в зависимости от глубины залегания торфа // Химия твердого топлива. 2013. №3. С. 19-30.

Поступило в редакиию 6 ноября 2013 г. 
Chuhareva N.V. INFLUENCE OF HEAT TREATMENT ON COMPOSITION AND DIFFERENT TYPES OF PEAT PROPERTIES OF TOMSK AREA

National Research Tomsk Polytechnic University, Lenina, 30, Tomsk, 634034 (Russia)

The influence of heat treatment on the change in the group and the elemental composition of different types of peat, its chemical structure of the IR spectra and its paramagnetic properties investigated. It is shown that the effect persists after the heat treatment characteristics due torfoobrazovatelnymi processes, but the depth of transformation of the starting material by preheating determined by the type of peat.

Keywords: peat, thermal treatment, elemental composition, IR spectroscopy.

\section{References}

1. Tarnovskaja L.I., Maslov S.G., Smol'janinov S.I. Himija tverdogo topliva, 1988, no. 3, pp. 26-29. (in Russ).

2. Chuhareva N.V. Issledovanie kinetiki termicheski aktivirovannyh izmenenij sostava i svojstv torfjanyh guminovyh kislot. Avtoref. dis. ... kand. him. nauk. [Investigation of the kinetics of thermally activated changes in the composition and properties of peat humic acids: abstract of dissertation ... candidate of chemistry sciences]. Tomsk, 2003, 23 p. (in Russ).

3. Bazhenov D.A. Modelirovanie fiziko-himicheskih zakonomernostej nizkotemperaturnogo razlozhenija torfa: dis. ... kand. him. nauk. [Modeling physical and chemical laws of low-temperature decomposition of peat: dissertaton ... candidate of chemistry sciences]. Tomsk, 2000, 165 p. (in Russ).

4. GOST 28245-89. Torf. Metody opredelenija botanicheskogo sostava i stepeni razlozhenija. [State Standard 28245-89. Peat. Methods for determination of the botanical composition and degree of decomposition]. Moscow, 2006, 7 p. (in Russ).

5. GOST 11305-83. Torf. Metody opredelenija vlagi. [State Standard 11305-83. Peat. Methods for determination of moisture]. Moscow, 1988, 8 p. (in Russ).

6. GOST 11306-83. Torf i produkty ego pererabotki. Metody opredelenija zol'nosti. [State Standard 11306-83. Peat and its products. Methods for determination of ash]. Moscow, 1995, 8 p. (in Russ).

7. GOST 6382-2001. Toplivo tverdoe mineral'noe. Metody opredelenija vyhoda letuchih veshhestv. [State Standard 6382-2001. Solid mineral fuel. Methods for determining the release of volatile substances]. Moscow, 2002, 20 p. (in Russ).

8. Lishtvan I.I., Korol' N.T. Osnovnye svojstva torfa i metody ih opredelenija. [The basic properties of peat and methods of their determination]. Minsk, 1975, 320 p. (in Russ).

9. Fadeeva V.P., Tikhova V.D., Nikulicheva O.N. Journal of analytical chemistry, 2008, vol. 63, no. 11, pp. 1094-1106.

10. Rakovskij V.E., Pigulevskaja L.V. Himija i genezis torfa. [Chemistry and genesis of peat]. Moscow, 1978, 231 p. (in Russ).

11. Lishtvan I.I. Himija tverdogo topliva, 1996, no. 3, pp. (in Russ).

12. Larina G.V., Ivanov A.A., Kazanceva N.A. Vestnik TGPU, 2009, issue 3(81), pp. 110-115. (in Russ).

13. Harrison B., Ellis J., Broadhurst D., Reid K., Goodacre R. and Priest F.G. Journal of the institute of Brewing, 2006, vol. 112, no. 4, pp. 333-339.

14. Tarnovskaja L.I. Zakonomernosti izmenenija gruppovogo sostava torfa v processe termoliza: dis. ... kand. tehn. nauk. [Regularities of changes in group composition of peat during thermolysis: dissertaton ... candidate of technical sciences]. Tomsk, 1985, 199 p. (in Russ).

15. Maryganova V.V., Bambalov N.N., Stiguckij V.P., Parmon S.V. Himija tverdogo topliva, 2013, no. 3, pp. 19-30. (in Russ). 